\title{
The Clinical Importance of the Heterogeneity of HER2 neu
}

\author{
Enrique Davila ${ }^{a}$ Kip Amazon ${ }^{b}$ \\ ${ }^{a}$ Aventura Comprehensive Cancer Center, and ${ }^{b}$ Department of Pathology, \\ Aventura Hospital and Medical Center, Aventura, Fla., USA
}

\section{Key Words}

HER2 neu $\cdot$ Herceptin · Trastuzumab · Breast cancer · Treatment

\begin{abstract}
We report on a patient with breast cancer in whom there were areas of the tumor that were $3+$ positive and negative for HER2 neu by immunohistochemistry, adjacent to each other. Depending on the area tested the results were completely different. The clinical implications are important. We recommend retesting a large portion of the tumor in all cases of initially negative test results.
\end{abstract}

\section{Introduction}

The importance of HER2 neu testing in breast cancer has been emphasized extensively. The recommended methods of testing for HER2 neu, its appropriate interpretation and the clinical consequences have also been the subject of extensive reviews [1,2]. When a tissue sample is adequately processed and interpreted by an experienced individual, in the presence of adequate controls, the results of the test are deemed to be reliable and do not require retesting. The heterogeneity of HER2 neu expression by immunohistochemistry (IHC) and/or fluorescence in situ hybridization (FISH) testing has also been studied with discrepant results [3-5] and guidelines have been issued regarding the intratumoral heterogeneity of HER2 neu expression by FISH [6]. However, the simultaneous coexistence of areas of negative expression and a $3+$ expression by IHC on immediately adjacent tumor cells has not been discussed.

\section{Case Report}

A 63-year-old woman underwent mammograms, ultrasound and magnetic resonance imaging of the breasts for mammographically detected, suspicious abnormalities. The larger abnormality in the left breast at 11 o'clock was shown to be a hyalinazing, infiltrating duct cell carcinoma of the breast with negative estrogen receptors ( $0 \%$ ), negative progesterone receptors $(0 \%)$ and negative HER2 neu oncoprotein expression (Ventana Medical Systems, Tucson, Ariz., USA), all by IHC with appropriately positive controls. The MIB-1 was high (76\%), the CK5 was positive (70\%) and the epidermal growth 


\begin{tabular}{|c|c|c|c|}
\hline $\begin{array}{l}\text { Cose Reports in } \\
\text { Ona.ayly }\end{array}$ & $\begin{array}{l}\text { Case Rep Oncol 2010;3:268-271 } \\
\text { D0I: } 10.1159 / 000319020\end{array}$ & Published online: July 24, 2010 & $\begin{array}{l}\text { @ } 2010 \text { S. Karger AG, Basel } \\
\text { ISSN 1662-6575 } \\
\text { www.karger.com/cro }\end{array}$ \\
\hline
\end{tabular}

factor receptor was also positive (90\%). A biopsy of a much smaller lesion revealed lobular neoplasia. The patient elected to have a left mastectomy and sentinel node biopsy and a prophylactic right simple mastectomy. The final pathology revealed a $2.5-\mathrm{cm}$, infiltrating, poorly differentiated duct cell carcinoma with clear margins. The Nottingham histologic score was 8 (Grade III), the estrogen and progesterone receptors were again negative (0), but the HER2 neu by IHC was positive $(3+)$. There was also lobular neoplasia in the vicinity. A total of 8 nodes were negative for metastasis by histology and IHC. The contralateral breast revealed fibrocystic mastopathy with intraductal microcalcifications and duct epithelial hyperplasia. The patient is Jewish Ashkenazi and has a positive family history of breast cancer with negative BRCA 1 and 2. The patient was started on adjuvant chemotherapy with trastuzumab, carboplatin and docetaxel.

The histopathology of the tumor was reviewed again, attempting to explain the disparity of the results, and we found that the majority of tumor cells expressing 3+ positivity for HER 2 neu by IHC were surrounding a defined area of the same histologic tumor that was negative for HER2 neu, by the same IHC. Fig. 1 shows a whole mount of the tumor on a glass slide stained with IHC for HER2 neu, showing malignant cells expressing $3+$ positivity for HER2 neu adjacent to negative expression. Furthermore, in the area of HER2 neu negativity, we were able to identify the needle tract left by the biopsy needle (schematically represented by two parallel lines), and a small square was amplified to higher power showing the junction between HER2-positive and -negative zones (ig. 2).

\section{Discussion}

When the testing for HER2 neu results in 3+ positivity by IHC or HER2 neu gene amplification by FISH testing, the patient is treated with medications targeting this receptor. Assuming accurate testing and interpretation, these tests are rarely, if ever, repeated again. The heterogeneity of HER2 neu results has been partially addressed [3-6], but the particular variability found in this unique case has not been addressed yet. The clinical consequences for this individual patient would have been serious if the HER2 neu positivity had gone undetected. We do not know the frequency with which a disparity of this degree occurs, but it is not even mentioned in reviews on this subject or consensus guidelines published previously. We therefore assume that it must be a rare phenomenon or one clearly underappreciated.

Recent tests using DNA microarray technology attempt to predict the risk of recurrence in patients with various cancers. The Oncotype DX ${ }^{\circledR}$ (Genomic Health Inc., Redwood City, Calif., USA) [7] is a commonly used test, accepted by the National Comprehensive Center Network [8], that analyzes the expression of 21 genes in breast tumors and reports a score that correlates with an estimated percentage chance of distant tumor recurrence. Occasionally, in the practice of clinical oncology, experienced physicians find large inexplicable discrepancies between the risk of recurrence assessed by the available clinical information and their individual experience and that reported by the test itself. The result of the risk as assessed by the Oncotype $\mathrm{DX}^{\circledR}$ relies greatly on the HER2 neu expression. There are also reports of patients with HER2 neu-negative breast cancers that have responded to therapy with trastuzumab. A central review of HER2 neu results has also been done in large trials with concordant results found only in $81 \%$ of the samples. However, the methodology did not include testing of the same specimen on which the original test had been done [9]. Finally, changes in HER2 neu results have also been reported in the same tumor at different times [10]. Cases similar to the one reported here offer an obvious potential explanation for these disparities and unexpected responses to therapy.

The clinical consequences of failing to identify the correct expression of HER2 neu are serious; therefore, we suggest that in patients in whom the original biopsy results of HER2 neu are negative, by any testing method, a retesting of a larger sample of the tumor should be done. 


\begin{tabular}{c|l|l|l}
$\begin{array}{c}\text { Cose Reports in } \\
\text { Onduly }\end{array}$ & $\begin{array}{l}\text { Case Rep Oncol 2010;3:268-271 } \\
\text { Dol: } 10.1159 / 000319020\end{array}$ & & $\begin{array}{l}\text { Published online: July 24, 2010 } \\
\text { ISSN 1662-6575 } \\
\text { www.karger.com/cro }\end{array}$ \\
\hline
\end{tabular}

Fig. 1. A whole mount of the tumor on a glass slide stained with IHC for HER2 neu showing malignant cells expressing 3+ positivity for HER2 neu adjacent to negative expression (small square). Two parallel lines: schematic representation of the needle tract left by the biopsy needle.

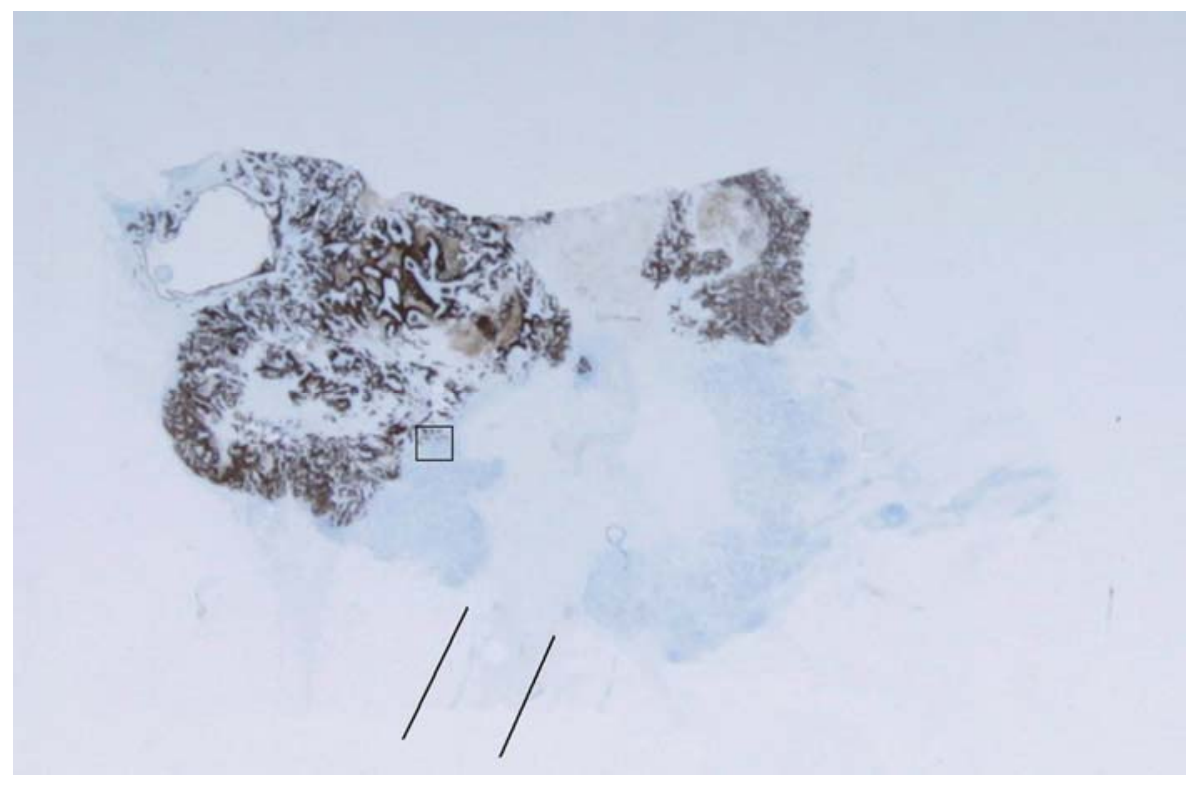

Fig. 2. Amplification of small square in figure 1. Junction between HER2-positive and -negative zones.

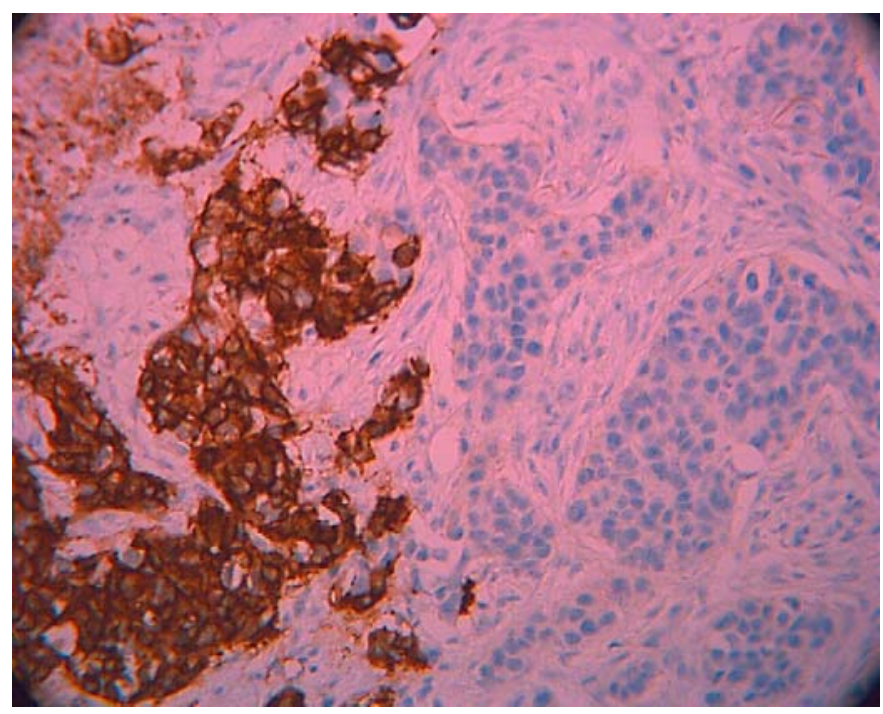




\section{References}

1 Wolff AC, Hammond EH, Schwartz JN, et al: American Society of Clinical Oncology/College of American Pathologists guideline recommendations for human epidermal growth factor receptor 2 testing in breast cancer. J Clin Oncol 2007;25:118-145.

2 Hudis CA: Trastuzumab - mechanism of action and use in clinical practice. N Engl J Med 2007;357:39-51.

-3 Glokner S, Buurman H, Kleeberger W, et al: Marked intratumoral heterogeneity of c-myc and CyclinD1 but not of c-erbB2 amplification in breast cancer. Lab Invest 2002;82:1419-1426.

-4 Lewis JT, Ketterling RP, Halling KC, et al: Analysis of intratumoral heterogeneity and amplification status in breast carcinomas with equivocal (2+) HER2 immunostaining. Am J Clin Pathol 2005;124:273-281.

5 Miller DV, Jenkins RB, Lingle WL, et al: Focal HER2/neu amplified clones partially account for discordance between immunohistochemistry and fluorescence in-situ hybridization results: data from NCCTG N9831 intergroup adjuvant trial. ASCO Annual Meeting Proceedings 2004;22:568.

-6 Vance GH, Barry TS, Bloom KJ, et al: Genetic heterogeneity in HER2 testing in breast cancer: panel summary and guidelines. Arch Pathol Lab Med 2009;133:611-612.

7 Paik S, Tang G, Shak S, et al: Gene expression and benefit of chemotherapy in women with node-negative, estrogen receptor-positive breast cancer. J Clin Oncol 2006;24:3726-3734.

8 Breast cancer: Practice guidelines in oncology. National Comprehensive Center Network, Inc.: MS-17 v.1.2010 09/18/2009. NCCN.org

\$9 Perez EA, Suman VJ, Davidson NE, et al: HER2 testing by local, central and reference laboratories in specimens from the North Central Cancer Treatment Group N9831 intergroup adjuvant trial. J Clin Oncol 2006;24:3032-3038.

10 Burstein HJ, Harris LN, Gelman R, et al: Preoperative therapy with trastuzumab and paclitaxel followed by sequential adjuvant doxorubicin/cyclophosphamide for HER2 overexpressing stage II or III breast cancer: a pilot study. J Clin Oncol 2003;21:46-53. 